\title{
The value of chosen diagnostic tools in evaluating myocarditis in children and adolescents
}

\author{
Szymon Price ${ }^{1}$, Aleksandra Bodys ${ }^{1}$, Adrianna Celińska1', Agata Rawiak1, Radosław Pietrzak², \\ Łukasz A. Małek³, Marzena Barczuk-Falęcka ${ }^{4}$, Michał Brzewski', Bożena Werner ${ }^{2}$ \\ 'Student Scientific Circle, Department of Paediatric Cardiology and General Paediatrics, Medical University of Warsaw, \\ Warsaw, Poland \\ 2Department of Paediatric Cardiology and General Paediatrics, Medical University of Warsaw, Warsaw, Poland \\ ${ }^{3}$ Faculty of Rehabilitation, Józef Piłsudski University of Physical Education in Warsaw, Warsaw, Poland \\ ${ }^{4}$ Department of Paediatric Radiology, Medical University of Warsaw, Warsaw, Poland
}

\section{ABSTRACT}

Introduction: Myocarditis is an inflammatory disease of the myocardium. Paediatric myocarditis is frequently overlooked due a misleading presentation when characteristic symptoms are lacking.

Aim of the study: The aim of our study was to assess the clinical presentation of myocarditis in children, and the sensitivity and usefulness of chosen tests for diagnosing this disease.

Material and methods: A retrospective chart review of paediatric patients with myocarditis was performed, where electrocardiography (ECG) and biomarker test results (leucocytes number, creatine kinase - CK, creatine kinase myocardial band - CKMB, troponin I, C-reactive protein - CRP, N-terminal precursor of natriuretic peptide type $\mathrm{B}$ - NT-proBNP) at admission and discharge were analysed along with echocardiography and cardiac magnetic resonance (CMR).

Results: Thirty-one cases were gathered, of which the majority presented with cardiac (90.3\%) or respiratory $(61.3 \%)$ symptoms. In most cases, normal or only slightly lowered ejection fraction (EF) was observed (mean 62.9\%, 95\% CI 60.6-65.1\%). ECG changes, cardiac troponin I, and CMR proved the most sensitive tests with respective sensitivities of $96.8 \%$ (95\% CI 83.3-99.9\%), 96.7\% (95\% CI 82.78-99.9\%), and 100\% (95\% CI 83.2-100\%). At discharge, levels of inflammatory and myocardial necrosis marker concentrations were significantly lower, and ejection fraction was significantly improved compared to ejection fraction at admission. CMR changes (i.e. signs of inflammation, delayed enhancement) were usually located in the inferolateral basal and mid-ventricular segments of the left ventricle. CRP, CK, and CKMB at admission correlated with the length of hospital stay.

Conclusions: Cardiac troponin, ECG changes, and cardiac magnetic resonance are highly sensitive tests for myocarditis in children. The initial values of biomarkers (concentration of CRP and activities of CK and $\mathrm{CKMB}$ ) correlate with the length of hospital stay. Myocarditis in children is most commonly located in the inferolateral wall of the left ventricle.

\section{KEY WORDS:}

myocarditis, cardiac magnetic resonance, troponin, biomarkers.

\section{ADDRESS FOR CORRESPONDENCE:}

Bożena Werner, Department of Paediatric Cardiology and General Paediatrics, Medical University of Warsaw, 63A Żwirki i Wigury St., 02-091 Warsaw, Poland, e-mail: bozena.werner@wum.edu.pl 


\section{INTRODUCTION}

Myocarditis (MC) is an inflammatory disease of the myocardium, usually of infectious origin. It most often occurs as a complication of viral infections [1]. Until the 1990s, the most frequently identified viruses in North America and Western Europe were enteroviruses (including the Coxsackie B). Nowadays, parvovirus B-19 and human herpesvirus 6 are the most frequently found viruses [2]. The incidence of this disease is difficult to assess because of its inherently nonspecific presentation. Patients usually present with tachycardia, tachypnoea, dyspnoea, chest pain, weakness, fever or arrhythmias [1]. These symptoms are also commonly seen in respiratory tract and gastrointestinal infections, and thus there is a significant risk of overlooking myocarditis. Moreover, some children presenting with nausea and emesis or diarrhoea may be misdiagnosed as having acute gastritis. Furthermore, in extreme cases, myocarditis may present as a fulminant haemodynamic collapse and sudden death [3]. Indeed, myocarditis is the most common cause of cardiac failure in healthy children [4]. In a retrospective study by Sparrow et al. acute myocarditis was reported as a cause of sudden cardiac death in up to $12 \%$ of young adults [5].

Three phases of myocarditis may be distinguished. The first phase is caused by direct cellular damage by the infectious agent. This is an acute phase, which lasts for a few days. The second phase is sub-acute and involves the host's innate immune response targeting infected cells, which lasts from a few days up to several months. A third, chronic phase is possible and may lead to dilated cardiomyopathy (DCM). The main treatments are supportive and symptom-based care [6].

Any clinical suspicion of MC is supported by clinical signs and symptoms together with electrocardiograms, echocardiography, and cardiac necrosis markers such as troponin, creatine kinase (CK), markers of inflammation, such as C-reactive protein (CRP), leucocytosis, and cardiac magnetic resonance findings (CMR). Endomyocardial biopsy (EMB), using the "Dallas criteria", has been identified as the gold standard in the diagnosis, but due to sampling errors the procedure's invasiveness and possible severe complications result in EMB being rarely performed whilst CMR has become the primary non-invasive tool used in clinical practice $[7,8]$. The utility of further enhancing CMR is facilitated by novel approaches for characterising tissue such as time-resolved assessment of gadolinium wash-out, T1 mapping, T2 mapping, parametric imaging, and the combination of imaging criteria with serum markers [7].

Our study aims were to assess the clinical presentation of myocarditis in children and the sensitivity and usefulness of chosen tests used for diagnosing this disease. We also aimed to assess changes in the aforementioned parameters between patients' admission and discharge. And finally, imaging obtained by CMR and echocardiography were also included in our analysis.

\section{MATERIAL AND METHODS}

We retrospectively collected data from patients (from an electronic database and paper documentation) who had been diagnosed with acute myocarditis (ICD-10 I40) between 1.01.2008 and 31.12.2017 at a paediatric cardiology ward. A clinical suspicion of myocarditis was established by a team of specialists in paediatric cardiology, based on anamnesis, physical examination, and additional tests. CMR was performed in most cases. All patients were evaluated for hospitalisation duration and clinical findings along with the outcomes of additional tests, i.e. electrocardiography (ECG) and laboratory testing that included white blood cell count (WBC), lymphocyte percentage, CRP, cardiac-specific troponin I - cTnI, N-terminal precursor of natriuretic peptide type B (NT-proB$\mathrm{NP}), \mathrm{CK}$, and creatine kinase myocardial band fraction (CKMB) as well as viral serology consisting of parvovirus B19, herpes type 6, Coxsackie B, influenza, and parainfluenza. Echocardiography and CMR imaging were also performed. An additional consideration was urine drug testing in adolescent patients [2].

Clinical presentations were divided into cardiac symptoms (chest pain or discomfort, syncope), respiratory symptoms (cough, dyspnoea, rhinorrhoea), and gastro-intestinal symptoms (abdominal pain, nausea, vomiting, diarrhoea). The heart rate was compared to reference values according to age and gender, and the blood pressure according to age and height [9-11]. An ECG was considered abnormal in the presence of: ST segment abnormalities, $\mathrm{T}$ abnormalities, heart block, and arrhythmias. Corrected QT intervals (QTc) were calculated using the Bazett formula [12]. Age-related normal ranges for laboratory test results were provided by the hospital's laboratory.

For echocardiography, the ejection fraction $(\mathrm{EF})$ and shortening fraction (SF) were evaluated. For CMR, the $\mathrm{EF}$ and the number and localisation of affected heart segments were analysed.

The obtained data were thus subjected to the appropriate statistical analysis. For the sensitivity calculations, data were divided into normal and abnormal according to age and gender within normal limits. Descriptive statistics and non-parametric tests were used to calculate mean results and ranges in order to compare outcomes between admission and discharge from hospital. The Spearman test was used to calculate correlation. Significance was taken as being $p<5 \%$. All tests were performed using Statistica 13.2 software.

\section{RESULTS}

In all, we found that 31 patients fitted the set criteria and were thus entered into the study database. The min- 
imum age was six days and maximum 17 years (mean $13.4 \pm 5.01) ; 25(80.6 \%)$ were male. The age distribution was non-parametric, peaking at the period of adolescence, i.e. 12-17 years of age (Fig. 1). Twenty-one of the cases $(67.7 \%)$ were confirmed by a CMR scan. None had undergone biopsy. At admission, 13 (56.5\%) of the study subjects had an abnormal BMI.

The mean time to admissions was 4 days \pm 3.36 and the mean length of hospital stay was 16 days \pm 6.05 .

\section{INVESTIGATION FINDINGS}

\section{Clinical observations}

The nature of the main complaints was cardiac $(n=28$; $90.3 \%)$, followed by respiratory $(n=19 ; 61.3 \%)$, and then gastrointestinal symptoms $(n=3 ; 9.7 \%)$.

\section{Electrocardiography}

Electrocardiographic examinations demonstrated abnormalities in 30 children (sensitivity of $96.8 \%, 95 \%$ CI $83.30 \%-99.92 \%)$. The most common findings were T-wave deviation (83.6\%) and ST-T changes (77.4\%). Right bundle branch block (RBBB) was discovered in $20 \%$ of cases. Pathological Q waves were observed in $7.4 \%$ of patients. The mean QTc value was $406 \mathrm{~ms}$ (95\% CI 378-435).

\section{Laboratory test results}

Laboratory markers were assayed at admission and discharge and compared below (Table 1). All parameters were significantly lower at discharge than at admission. The sensitivities of tests (at 95\% confidence intervals) are shown in Table 2. A urinary drug scan was performed for three patients and was positive for THC (tetrahydrocannabinol) and amphetamine in one patient. Viral serology tests found that parainfluenza virus IgA and IgG were the most common $(n=8 ; 26 \%)$. We observed a statistically significant moderate to good positive correlation between CK/CKMB levels and hospitalisation duration (Spearman's $\rho=0.45$ and 0.71 , respectively; $p<0.05$; Fig. 2).

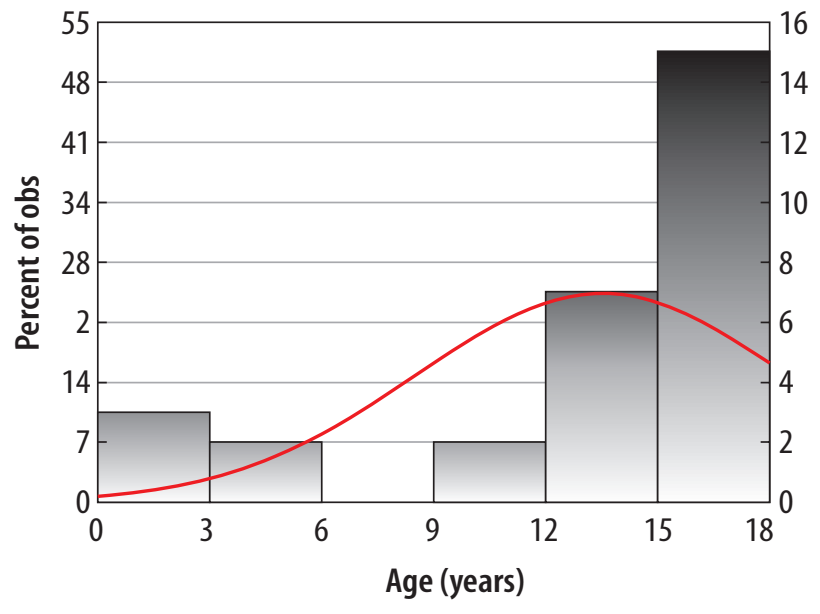

FIGURE 1. Age histogram

\section{Imaging}

Ejection fractions were measured by echocardiography and CMR. In children who underwent CMR $(n=20)$, abnormal EF was observed in $50 \%$ cases. Echocardiograms revealed reduced $\mathrm{EF}$ in nine patients $(23.1 \%)$, and the $\mathrm{EF}$ following echocardiography at discharge was significantly higher than at admission $(p<0.05)$ (Table 3). All patients met CMR criteria for MC (signs of inflammation and delayed enhancement); with $100 \%$ sensitivity, 95\% CI 83.16$100 \%$. The most commonly affected regions were the inferolateral, basal, and mid-ventricular segments (Figs. 3-6).

\section{DISCUSSION}

This study assessed the clinical presentation of children with myocarditis and the usefulness of commonly used investigations. Due to the extremely nonspecific clinical presentation of viral myocarditis, which includes symptoms of upper airway infection or gastrointestinal tract infection, this serious disease could easily be overlooked. Indeed, a recent study demonstrated that a third of young children presenting with a viral infection had subclinical myocarditis [13]. According to the literature, chest pain in children is also nonspecific; Ji et al. demonstrated that only $3.8 \%$ of cases of chest pain had a cardiac

TABLE 1. Laboratory markers at admission and discharge from hospital

\begin{tabular}{|c|c|c|c|c|c|c|c|c|c|}
\hline & \multicolumn{4}{|c|}{ Admission } & \multicolumn{4}{|c|}{ Discharge } & \multirow[t]{3}{*}{$p^{b}$} \\
\hline & \multirow[t]{2}{*}{$n$} & \multicolumn{3}{|c|}{ Parameter } & \multirow[t]{2}{*}{$n$} & \multicolumn{3}{|c|}{ Parameter } & \\
\hline & & Mean $(95 \% \mathrm{CI})$ & Range $^{\mathrm{a}}$ & SD & & Mean $(95 \% \mathrm{CI})$ & Range $^{\mathrm{a}}$ & SD & \\
\hline WBC $\left(10^{9} / \mathrm{I}\right)$ & 31 & $7.5(6.7-8.3)$ & $5.65-9.3$ & 2.1 & 28 & $7.2(6.42-7.94)$ & $5.6-8.4$ & 2.1 & 0.31 \\
\hline Lymph (\%) & 31 & $29.9(25.4-34.4)$ & $21.2-36.2$ & 12 & 28 & $36.2(32.1-40.4)$ & $31.2-40.6$ & 10.6 & $<0.01$ \\
\hline CRP (mg/l) & 31 & $4.7(3.1-6.2)$ & $1.2-6.5$ & 4.2 & 28 & $0.6(0.2-0.9)$ & $0-0.9$ & 0.8 & $<0.0001$ \\
\hline cTnl (ng/l) & 29 & $3.9(1.7-6.1)$ & $0.6-4.3$ & 5.8 & 29 & $0.9(-0.2-2)$ & 0 & 3 & $<0.0001$ \\
\hline NT-proBNP (pg/ml) & 13 & $302(117-486)$ & $44-442.3$ & 305.4 & 8 & $85.5(31-140)$ & $21-131.5$ & 65.2 & 0.027 \\
\hline CK (U/I) & 27 & $448(326-570)$ & 191-745 & 308 & 25 & $82.4(42.2-122.5)$ & $45-81$ & 97.2 & $<0.0001$ \\
\hline CKMB (ng/ml) & 28 & $40.4(25.6-55.3)$ & $8-60.8$ & 38.3 & 19 & $8.1(-0.4-16.6)$ & $1.7-5.2$ & 17.6 & 0.0005 \\
\hline
\end{tabular}

$C R P$ - C-reactive protein, cTnI - cardiac-specific troponin I, NT-proBNP - N-terminal precursor of natriuretic peptide type B, CK - creatine kinase, CKMB - creatine kinase myocardial band, aranges reported as lower and upper quartile, ${ }^{b}$ calculated with Wilcoxon $t$-test 
TABLE 2. Sensitivity of laboratory diagnostic tests on admission

\begin{tabular}{|l|c|c|c|c|c|}
\hline Biomarker & $n$ & $\begin{array}{c}n \\
\text { abnormal }\end{array}$ & $\begin{array}{c}n \\
\text { normal }\end{array}$ & $\begin{array}{c}\text { Sensi- } \\
\text { tivity } \\
(\%)\end{array}$ & $95 \%$ CI \\
\hline CRP & 31 & 28 & 3 & 90.3 & $74.25-97.96$ \\
\hline CInl & 30 & 29 & 1 & 96.7 & $82.78-99.92$ \\
\hline BNP $(<20)$ & 13 & 11 & 2 & 84.6 & $54.55-98.08$ \\
\hline CK & 26 & 16 & 10 & 61.5 & $40.57-79.77$ \\
\hline CKMB & 28 & 21 & 7 & 75 & $55.13-89.31$ \\
\hline
\end{tabular}

CRP - C-reactive protein, CTnI - cardiac-specific troponin I, BNP - B-type natriuretic peptide, CK - creatine kinase, CKMB - creatine kinase myocardial band

origin [14]. Therefore, tools other than physical examination are required to diagnose a child with myocarditis.

Almost all our patients presented with chest pain, which is more typical for adult than children's myocarditis $[3,15]$. This may be easily explained by patients mostly being older children, fully capable of feeling and expressing their pain [15]. Chest pain is also a symptom that may be alarming to parents and prompt them to visit a doctor. Previous research has indicated that myocarditis may be confused with gastroenteritis or respiratory infections $[3,16,17]$. In our study, 11 patients presented with an upper respiratory tract infection, thus confirming its common occurrence. Gastroenteritis was less common, affecting four patients.

Most study patients were male, similar to previous studies, and 13 (56.5\%) of those who were weighed and measured at admission had an abnormal BMI, which is a much higher rate than the average for healthy children in Poland $[3,18]$. This may suggest that male gender and high BMI could be potential risk factors. Also, in one patient a drug aetiology may be considered because a urine drug screen proved positive for THC and amphetamine; the latter agent being a known cause of myocarditis [17]. Viral serological testing was also carried out, and parainfluenza was the most frequently identified, even though it is not commonly associated with myocarditis $[19,20]$. Parainfluenza could therefore be a meaningful agent in myocarditis in our local population. Nevertheless, it should be emphasised that viral serology tests are unable to establish the cause of myocarditis, and their usefulness in clinical practice is low, as has been demonstrated in previous studies [19, 21].

The most sensitive parameters in ECG were T-wave abnormalities and ST segment elevation or depression ( $83.9 \%$ and $77.4 \%$, respectively). RBBB was also a relatively common finding. In healthy children, only $0.11 \%$ have RBBB [22] and 1-34.1\% exhibit ST elevation [23]. Such changes in ECG were often found in patients with myocarditis and are linked to host-mediated and viralinduced inflammation [24]. At discharge, the number of patients with ST segment abnormalities was significantly lower $(p<0.001)$ than at admission, but the T-wave abnormalities persisted in most patients. Thus, T-wave abnormalities could be a better marker for patients who present late after the onset of symptoms. The mean QTc
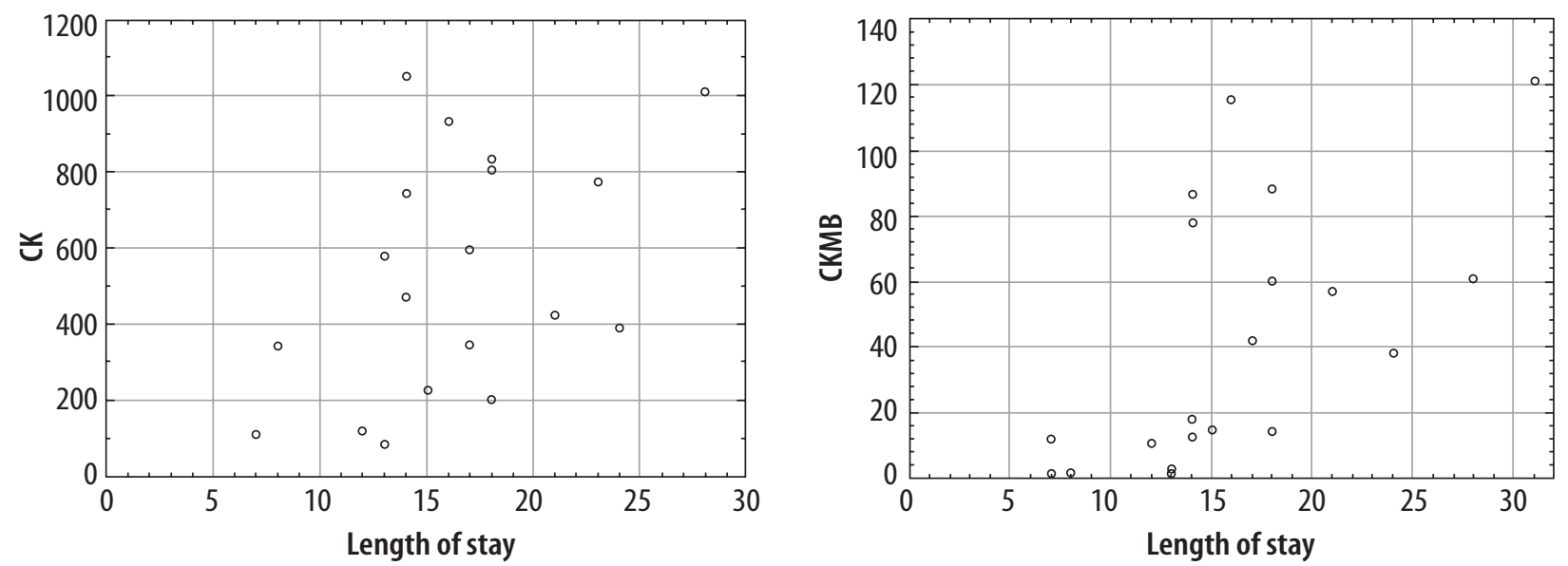

FIGURE 2. Scatterplot of creatine kinase (CK) and creatine kinase myocardial band (CKMB) on admission against length of stay

TABLE 3. Ejection fractions and shortening fractions before and after hospitalisation

\begin{tabular}{|c|c|c|c|c|c|c|c|c|c|}
\hline & \multicolumn{4}{|c|}{ Admission } & \multicolumn{4}{|c|}{ Discharge } & \multirow[b]{3}{*}{$p^{b}$} \\
\hline & \multirow[t]{2}{*}{$n$} & \multicolumn{3}{|c|}{ Parameter } & \multirow[t]{2}{*}{$n$} & \multicolumn{3}{|c|}{ Parameter } & \\
\hline & & $\mathrm{M}(95 \% \mathrm{Cl})$ & Range $^{\mathrm{a}}$ & SD & & $M(95 \% \mathrm{Cl})$ & Range $^{a}$ & SD & \\
\hline $\mathrm{EF}$ (CMR) & 21 & $57.9(55.2-60.6)$ & $55-61.5$ & 5.9 & - & - & - & - & - \\
\hline EF & 31 & $62.9(60.6-65.1)$ & $59-66$ & 6.2 & 23 & $67.6(64.2-71.1)$ & $62-74$ & 7.9 & 0.041 \\
\hline SF & 26 & $34.8(32.8-36.8)$ & $31-37$ & 5.0 & 16 & $41.1(36.6-45.5)$ & $36-44$ & 8.4 & 0.045 \\
\hline
\end{tabular}

EF- ejection fraction, SF- shortening fraction, ${ }^{a}$ ranges reported as lower and upper quartile, ${ }^{b}$ calculated with Wilcoxon $t$-test 

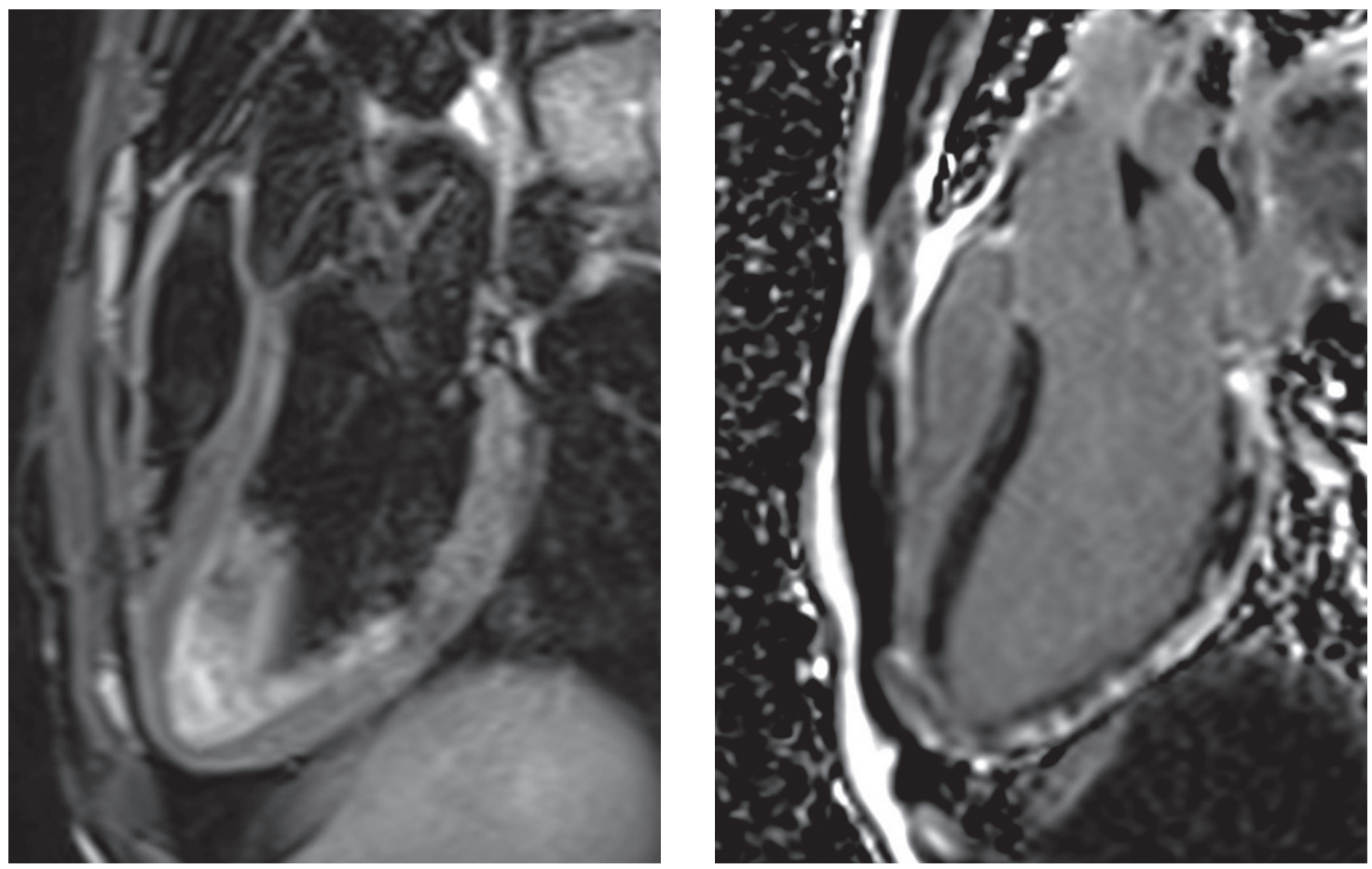

FIGURE 3. Localisation of changes in CMR. 3-chamber view. Oedema (left) and the midmyocardial and subepicardial delayed enhancement areas (right) of lateral and inferior wall
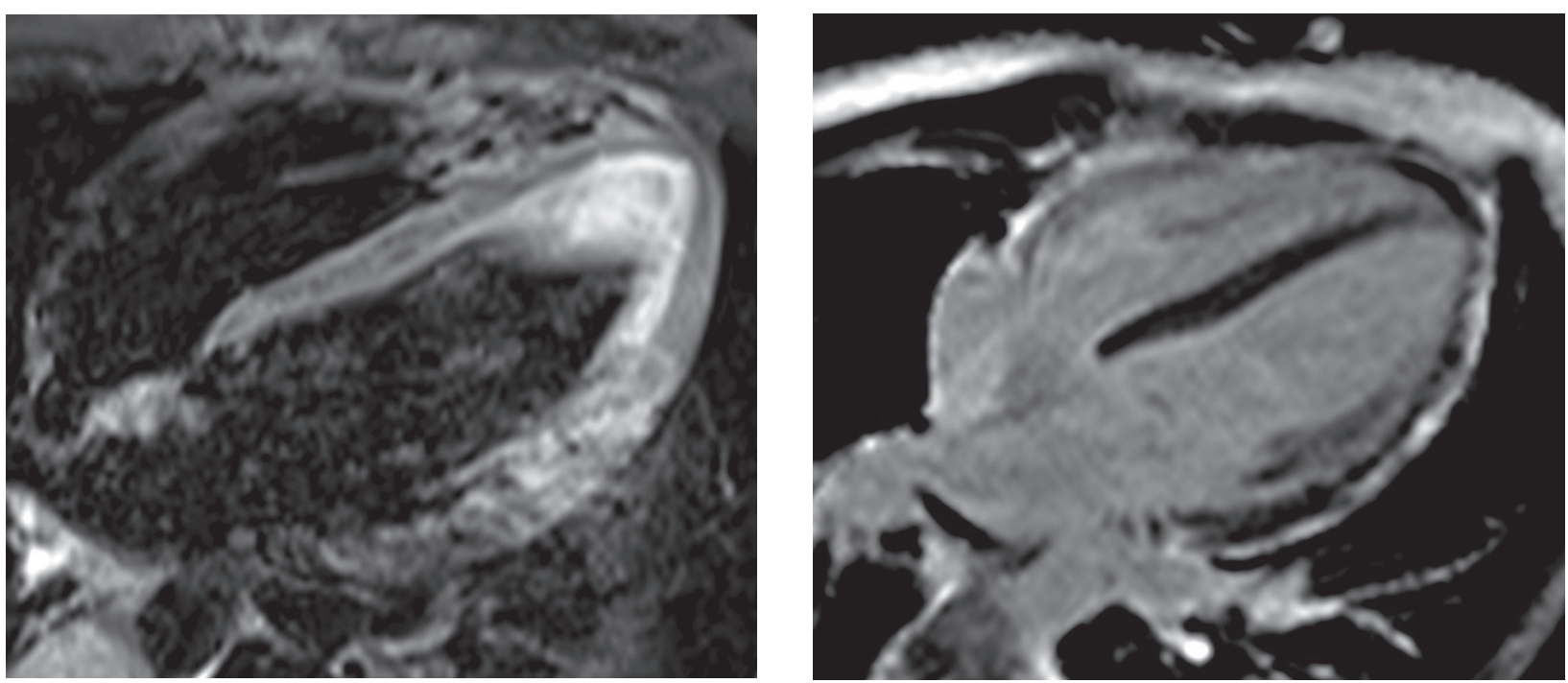

FIGURE 4. Localisation of changes in CMR. 4-chamber view. Oedema (upper) and the midmyocardial and subepicardial delayed enhancement areas (lower) of the lateral wall

in our patients was within the normal range. Yuan et al. [25] showed that a prolonged QTc was prognostic of a fulminant course of myocarditis, which is consistent with the results of our study, where patients presented without signs of fulminant myocarditis.

We demonstrated a high sensitivity of troponin I, CRP, CK, and BNP [26]. In our study the best biomarker for myocarditis was cardiac troponin I. Other studies are conflicting; some have demonstrated a sensitivity of cardiac troponin $\mathrm{T}$ lower than that shown in our study at $76 \%$ or $53 \%$ - probably due to excessively high cutoff values applied in these studies $(0.05$ and $0.3 \mathrm{ng} / \mathrm{ml}$, respectively), whereas the negative predictive value of troponin I in the second study was only $56 \%$ [27, 28]. Nevertheless, Kelley et al. have shown that in adult myocarditis patients, cTnI has a specificity as high as $94 \%$ [29]. A high sensitivity and specificity of cardiac troponin $\mathrm{T}$ has been demonstrated (respectively, $100 \%$ and $85 \%$ ) for myocarditis in children with a cut-off value of $0.01 \mathrm{ng} / 1$ [30, 31]. Our study therefore supports the hypothesis that troponin is a highly specific biomarker for diagnosing MC in children. Moreover, due to the correlation of CKMB and CK levels with the duration of hospitalisation, a combination of these parameters may potentially be useful in 

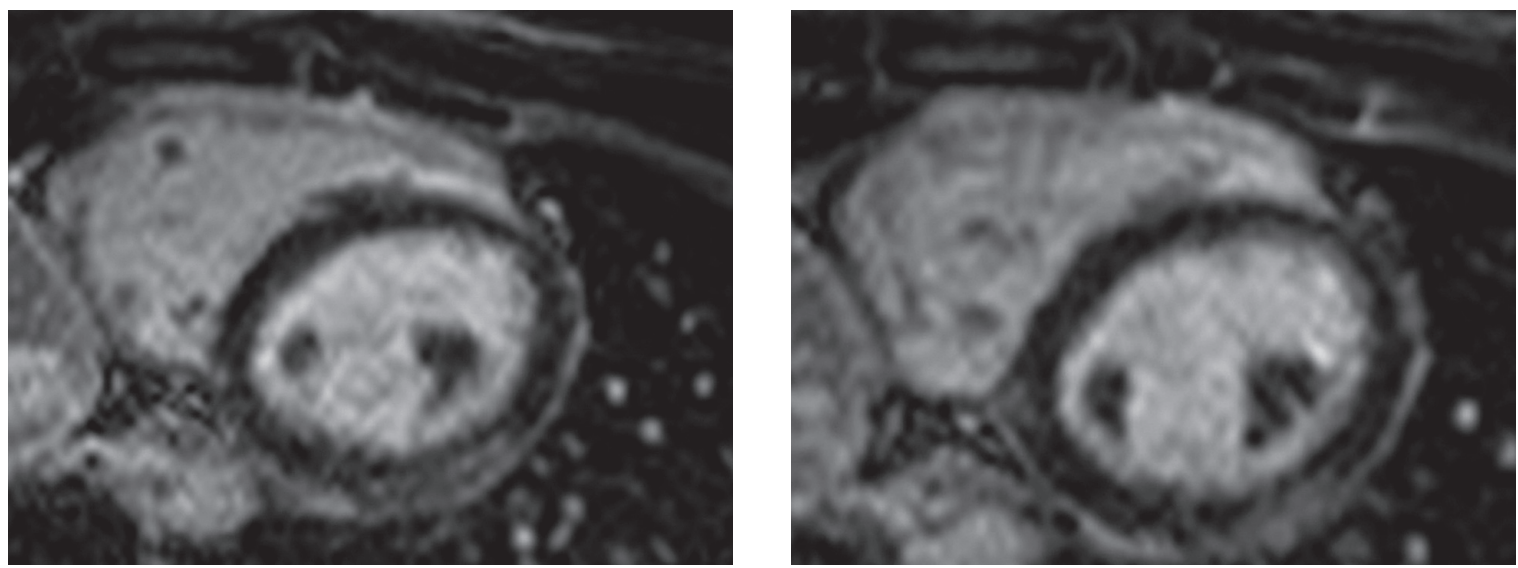

FIGURE 5. Localisation of changes in CMR. Short-axis view. Midmyocardial and subepicardial late gadolinium enhancement areas of the lateral wall.

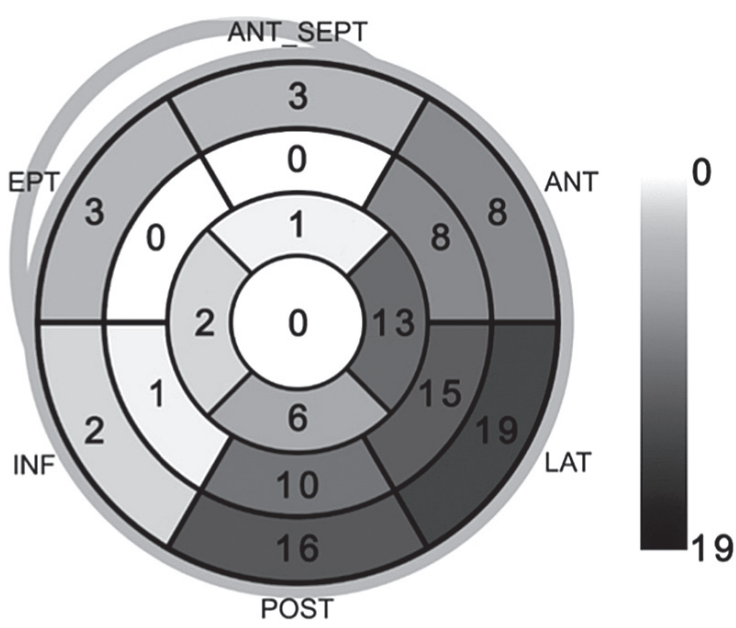

FIGURE 6. Localisation of myocarditis

assessing the severity of myocarditis. Further studies are necessary for confirmation.

The EF in CMR and echocardiography were only slightly lowered for our patients, demonstrating that acute myocarditis in children often presents without severe cardiac stress [13]. In adult patients, CMR has been identified as a specific and sensitive method for identifying myocarditis [32, 33]. Our study confirms such high sensitivity because at least part of the myocardium was inflamed and/or had delayed enhancement in all the cases examined. The most commonly affected areas were the basal and mid-ventricular inferolateral segment of the left ventricle. Those findings are in accordance with corresponding adult studies [34]. Some previous studies have found comparable areas to be affected $[35,36]$. The reason for such a localisation of myocarditis remains unknown; a possible factor may be the proximity of the pericardial sac.

Our study was designed to analyse the sensitivity of biomarkers and compare their levels at admission and discharge in a paediatric cardiology ward in order to evaluate their clinical usefulness for diagnosing and monitor- ing myocarditis. Few such studies have been conducted, and some of those more prominent (e.g. on troponins) were carried out when tests were less accurate than they are now [28].

The study is limited by the moderate number of patient subjects, although the numbers were large enough to draw accurate conclusions and obtain statistically significant results. In addition, this retrospective method led to certain data being unavailable. A further limitation was the lack of parametric imaging in CMR.

\section{CONCLUSIONS}

Cardiac troponin, ECG changes, and cardiac magnetic resonance are highly sensitive tests for myocarditis in children. The initial levels of biomarkers (CRP, CK, CKMB) correlate with the length of hospital stay. The most common localisation of myocarditis in the paediatric population studied was at the inferolateral wall of the left ventricle.

\section{DISCLOSURE}

The authors declare no conflict of interest.

\section{REFERENCES}

1. Suthar D, Dodd DA, Godown J. Identifying Non-invasive Tools to Distinguish Acute Myocarditis from Dilated Cardiomyopathy in Children. Pediatr Cardiol 2018; 39: 1134-1138.

2. Caforio AL, Pankuweit S, Arbustini E, et al. European Society of Cardiology Working Group on Myocardial and Pericardial Diseases. Current state of knowledge on aetiology, diagnosis, management, and therapy of myocarditis: a position statement of the European Society of Cardiology Working Group on Myocardial and Pericardial Diseases. Eur Heart J 2013; 34: 2636-48, 2648a-2648d.

3. Dominguez F, Kühl U, Pieske B, et al. Update on Myocarditis and Inflammatory Cardiomyopathy: Reemergence of Endomyocardial Biopsy. Rev Esp Cardiol (Engl Ed) 2016; 69: 178-187.

4. Freedman SB, Haladyn JK, Floch A, et al. Pediatric Myocarditis: Emergency Department Clinical Findings and Diagnostic Evaluation. Pediatrics 2007; 120: 1278-1285. 
5. Dettmeyer R, Baasner A, Schlamann M, et al. Role of virus-induced myocardial affections in sudden infant death syndrome: a prospective postmortem study. Pediatr Res 2004; 55: 947-952.

6. Wisotzkey BL, Soriano BD, Albers EL, et al. Diagnostic role of strain imaging in atypical myocarditis by echocardiography and cardiac MRI. Pediatr Radiol 2018; 48: 835-884.

7. Merchant Q, Haque A, Hasan BS. Management of acute myocarditis in children. J Pak Med Assoc 2013; 63: 803-811.

8. Friedrich MG, Sechtem U, Schulz-Menger J, et al. Cardiovascular Magnetic Resonance in Myocarditis: A JACC White Paper. J Am Coll Cardiol 2009; 53: 1475-1487.

9. Baccouche H, Mahrholdt H, Meinhardt G, et al. Diagnostic synergy of non-invasive cardiovascular magnetic resonance and invasive endomyocardial biopsy in troponin-positive patients without coronary artery disease. Eur Heart J 2009; 30: 2869-2879.

10. Kułaga Z, Litwin M, Grajda A, et al. Distribution of blood pressure in school-aged children and adolescents reference population. Stand Med, Pediatr 2010; 7: 853-864.

11. Ostrowska-Nawarycz L, Nawarycz T. Normy ciśnienia tętniczego u dzieci i młodzieży - doświadczenia łódzkie. Nadciśn Tętn 2007; 11: $138-150$.

12. Bazett HC. An analysis of the time-relations of electrocardiograms. Heart 1920; 7: 353-370.

13. Talmon G, Fink DL, Horowitz Y, et al. The prevalence of subclinical myocarditis among young with acute viral infection. Harefuah 2015; 154: 641-645, 676, 675.

14. Chun JH, Kim TH, Han MY, et al. Analysis of clinical characteristics and causes of chest pain in children and adolescents. Korean J Pediatr 2015; 58: 440-445.

15. Mahrholdt H, Wagner A, Deluigi CC, et al. Presentation, Patterns of Myocardial Damage, and Clinical Course of Viral Myocarditis. Circulation 2006; 114: 1581-1590.

16. Committee on Psychosocial Aspects of Child and Family Health; Task Force on Pain in Infants, Children, and Adolescents. The assessment and management of acute pain in infants, children, and adolescents. Pediatrics 2001; 108: 793-797.

17. Canter CE, Simpson KE. Diagnosis and Treatment of Myocarditis in Children in the Current Era. Circulation 2014; 129: 115-128.

18. Kułaga Z, Różdżyńska A, Palczewska I, et al. Percentile charts of height, body mass and body mass index in children and adolescents in Poland - results of the OLAF study. Stand Med, Pediatr 2010; 7 : 690-700.

19. Mahfoud F, Gärtner B, Kindermann M, et al. Virus serology in patients with suspected myocarditis: utility or futility? Eur Heart J 2011; 32: 897-903.

20. Kindermann I, Barth C, Mahfoud F, et al. Update on Myocarditis. J Am Coll Cardiol 2012; 59: 779-792.

21. Romero-Gómez MP, Guereta L, Pareja-Grande J, et al. Myocarditis Caused by Human Parainfluenza Virus in an Immunocompetent Child Initially Associated with 2009 Influenza A (H1N1) Virus. J Clin Microbiol 2011; 49: 2072-2073.

22. Chiu SN, Wang JK, Wu MH, et al. Taipei Pediatric Cardiology Working Group. Cardiac conduction disturbance detected in a pediatric population. J Pediatr 2008; 152: 85-89.

23. Yoshinaga M, Iwamoto M, Horigome $\mathrm{H}$, et al. Standard Values and Characteristics of Electrocardiographic Findings in Children and Adolescents. Circ J 2018; 82: 831-839.

24. Tse G, Yeo JM, Chan YW, et al. What Is the Arrhythmic Substrate in Viral Myocarditis? Insights from Clinical and Animal Studies. Front Physiol 2016; 7: 308.

25. Hung Y, Lin WH, Lin CS, et al. The Prognostic Role of QTc Interval in Acute Myocarditis. Acta Cardiol Sin 2016; 32: 223-230.

26. Freedman SB, Haladyn JK, Thull-Freedman J, et al. Cardiac Troponins in Pediatric Myocarditis: In Reply. Pediatrics 2008; 121: 864.
27. Soongswang J, Durongpisitkul K, Nana A, et al. Cardiac troponin T: a marker in the diagnosis of acute myocarditis in children. Pediatr Cardiol 2005; 26: 45-49.

28. Lauer B, Niederau C, Kühl U, et al. Cardiac troponin T in patients with clinically suspected myocarditis. J Am Coll Cardiol 1997; 30: 1354-1359.

29. Kelley WE, Januzzi JL, Christenson RH. Increases of Cardiac Troponin in Conditions other than Acute Coronary Syndrome and Heart Failure. Clin Chem 2009; 55: 2098-2112.

30. Eisenberg MA, Greene-Hopkins I, Alexander ME, et al. Cardiac troponin $\mathrm{T}$ as a screening test for myocarditis in children. Pediatr Emerg Care 2012; 28: 1173-1178.

31. Al-Biltagi M, Issa M, Hagar HA, et al. Circulating cardiac troponins levels and cardiac dysfunction in children with acute and fulminant viral myocarditis. Acta Paediatr 2010; 99: 1510-1516.

32. Jeserich M, Konstantinides S, Pavlik G, et al. Non-invasive imaging in the diagnosis of acute viral myocarditis, Clin Res Cardiol 2009; 98: 753-763.

33. Schultz JC, Hilliard AA, Cooper LS, et al. Diagnosis and Treatment of Viral Myocarditis. Mayo Clin Proc 2009; 84: 1001-1009.

34. Yelgec NS, Dymarkowski S, GanameJ, et al. Value of MRI in patients with a clinical suspicion of acute myocarditis. Eur Radiol 2007; 17: 2211-2217.

35. Liu G, Yang X, Su Y, et al. Cardiovascular magnetic resonance imaging findings in children with myocarditis. Chin Med J (Engl) 2014; 127: 3700-3705.

36. Sachdeva S, Song X, Dham N, et al. Analysis of clinical parameters and cardiac magnetic resonance imaging as predictors of outcome in pediatric myocarditis. Am J Cardiol 2015;115: 499-504. 